\title{
Karl Marx e o nascimento da sociedade moderna
}

Edson Mendes Nunes Júnior ${ }^{1}$

Biografar Karl Marx significa entrar em um território de grandes incertezas, boatos e, acima de tudo, paixões. O pensador já foi, e ainda é, amado e odiado pelos seus escritos e atuação política, o que faz qualquer tentativa de narrar sua vida uma aventura sujeita a disputas de narrativas. Dentre os próprios estudiosos de Marx, como aponta José Paulo Netto (2006), há os marxólogos, que compreendem que a produção de Marx é reservada ao passado; os marxizantes, que separam de sua obra somente o que é conveniente a seus interesses; os marxistas acadêmicos, abarcando desde os dogmáticos até os autores que 'rompem' com Marx.

Michael Heinrich (2018), cientista político e professor de economia política da Universidade de Ciências Aplicadas de Berlim (HTW Berlin), executa a tarefa de realizar uma biografia de Marx através de uma análise minuciosa de documentos da MEGA $2^{2}$. Esta apreciação de textos, cartas e poemas permitiu compreender melhor que antigos biógrafos as escolhas, mudanças e acontecimentos relevantes da vida de Marx.

Além disso, o primeiro dos três volumes da biografia realizada por Heinrich (2018) busca contextualizar a vida de Karl Marx com seu

\footnotetext{
${ }^{1}$ Mestrando e Graduado em Ciência Política pela Universidade Federal do Estado do Rio de Janeiro (UNIRIO), Graduado em Relações Internacionais pelo IBMR. Email: mendesjr.edson@gmail.com.

${ }^{2}$ A MEGA (Marx-Engels-Gesamtausgabe) é a publicação de obras completas de Marx e Engels, incluindo cartas e textos. A primeira versão da MEGA teve que ser interrompida pelo assassinato de seu organizador David Riazánov. Nos anos 1970 foi iniciada a MEGA 2, de forma mais completa, permitindo aos biógrafos e estudiosos de Marx acesso a novas informações interessantes sobre o autor (HEINRICH, 2018).
} 
progresso teórico, partindo desde provas da época do ginásio até sua tese de doutorado, Diferença Entre a Filosofia Da Natureza De Demócrito a Epicuro (MARX, 2018a). O autor realiza uma análise da história e da construção do pensamento de Marx sem, entretanto, acompanhar duas hipóteses comuns: a de um progressismo da obra marxiana até alcançar seu ápice em O Capital (2004) e a de um corte epistemológico que divide seus escritos em dois momentos, o 'jovem Marx' e o 'velho Marx'. Esta última é sugerida por Louis Althusser (2015), que aponta para a aproximação de Marx com o materialismo, constatada nos Manuscritos Econômico-Filosóficos (2008) como um texto representante do momento do corte entre o jovem e o amadurecido Marx. Para Heinrich, há um processo de aprendizagem caracterizado por linhas de continuidade e rupturas de forma dinâmica, não aceitando a possibilidade de confinar partes de sua produção em classificações específicas como se houvesse um único momento de ruptura entre elas.

O livro é dividido em três capítulos, divididos em momentos de importantes rupturas ou, no mínimo, mudanças significativas na vida e/ou no pensamento de Marx. O primeiro capítulo investiga aspectos pouco conhecidos da juventude de Marx, além de uma análise da realidade concreta da cidade prussiana de Trier, onde Karl nasceu e passou sua juventude. Ainda que grande parte desse momento histórico de sua vida tenham se 'perdido' - visto que não há diários ou livro de memórias de Marx nessa época - a averiguação feita por Heinrich (2018) sobre a vida de seus pais, Heinrich Marx e Henriette Presburg, além da situação econômica da família e da própria cidade de Trier, ajudam a imaginar o contexto onde se passou sua infância e juventude. Diferente de outros autores, que já buscam encontrar em redações e trabalhos do ginásio, um aspecto revolucionário no pensamento de Marx, o biógrafo revela o interesse, ainda quando pequeno, em filosofia - provavelmente por conversas com seu pai e seu futuro sogro - e sua relação complexa 
com a religiosidade. Ao mesmo tempo em que é possível concluir que Marx e seus pais não cultivassem uma fé religiosa inabalável, a falta de entusiasmo e devoção presente nos seus trabalhos, quando comparado com outros alunos, pode levantar a hipótese de, no mínimo, existir alguma limitação na profundidade da sua crença no Deus cristão personificado.

Um dos pontos de destaque de sua redação Considerações de um rapaz acerca da escolha de uma profissão, escrita ainda no ginásio, é exatamente a presença da palavra “divindade" ao invés de "Deus". Contudo, são destacados também o forte enfoque social do texto, como vemos na seguinte passagem: “(...) Nossas relações na sociedade já começam, até certo ponto, antes mesmo de estarmos em posição de determina-las” (MARX, 2018b, p. 422). A frase rendeu interpretações sobre, por exemplo, uma semente do que se desenvolveria como o materialismo histórico no pensamento marxiano. Heinrich (2018), todavia, entende que esta observação pode ser resultado de conversas entre Marx e seu pai, devido a toda dificuldade que este passou para conseguir exercer sua profissão.

No segundo capítulo o autor aborda a ida de Marx para a Universidade de Bonn, apresentando a forma pela qual as faculdades funcionavam na época. Mulheres, por exemplo, eram proibidas de estudar e lecionar. Mas, se hoje um diploma já significa ter certos privilégios na sociedade que garantiram um acesso ao ensino superior, nos tempos de Marx essa relação era ainda mais intensa. Dificilmente, como aponta Heinrich (2018), encontrava-se alguém vindo de uma família de trabalhadores na faculdade. Aborda-se, também, a primeira crise de Karl, após sua mudança de objetivo, onde a literatura é abandonada para dar espaço ao interesse pela filosofia, em especial a hegeliana.

Entende-se como esta 'crise' relaciona-se com sua ida a Universidade de Berlim em 1876. Além de ser a primeira cidade grande onde Karl viveu, seus estudos permitiram contato próximo com 
professores que viviam o legado do debate intenso levantado por Friedrich Hegel, morto em 1831. Os estudos jurídicos e não jurídicos de Marx incentivaram sua vontade de dedicar-se a filosofia, como relatado em cartas a seu pai. As criações poéticas do autor, principalmente depois de um projeto de publicação que não foi possível levar a frente, foram deixadas de lado para dar espaço à reflexão.

Apesar de ignorados por outros biógrafos, Heinrich (2018) apresenta os poemas de Marx - influenciado, por exemplo, por Goethe para demonstrar que, diferente do que se pensava, não havia uma má qualidade nesses escritos, de caráter romântico. Existe uma evolução na forma pela qual Karl realiza seus poemas, alguns voltados a seu amor pela noiva que o acompanharia até o final de sua vida, Jenny Marx - com a qual compartilhava, inclusive, um interesse por Shakespeare - que revela a vontade de fazer experimentos que os unissem a temas filosóficos e literários com os quais havia entrado em contato. Marx abandona seu talento para poemas não necessariamente por uma frustração sobre a qualidade do que produzia, mas, como afirma em carta ao pai, pelo idealismo existente na arte, contestada pela sua potencialidade de mudar o mundo. E, para o biógrafo, é exatamente a crítica realizada por Hegel contra a arte romântica que impacta Marx, aproximando-o do hegelianismo.

Já no terceiro capítulo, Heinrich (2018) expõe a proximidade de Marx com os chamados 'jovens hegelianos’ e a filosofia da religião. Apesar de muitas vezes resumida a frase a religião é o "ópio do povo" (MARX, 2010, p.145), presente em sua Crítica a Filosofia do Direito de Hegel, o biógrafo revela como o estudo da religião foi fundamental para o desenvolvimento teórico de Marx e sua relação com os hegelianos. Na Prússia marcada por fortes discussões políticas no que diz respeito a religião, visto que o próprio Estado considerava-se cristão, levando 'jovens hegelianos' a uma posição mais radical contrária a religiosidade. A divisão 
na escola hegeliana é contestada por Heinrich (2018). Primeiro, devido ao erro de identificar os 'velhos hegelianos' como os 'hegelianos de direita', de caráter mais conservador, e os 'jovens hegelianos' como 'hegelianos de esquerda', progressistas ou revolucionários. Além do tratamento como sinônimos ser equivocado, há a dificuldade de encaixar alguns teóricos hegelianos em alguma destas classificações. No entanto, além da crítica materialista a religião representada por Ludwig Feuerbach, a qual Marx entra em contato e criticará mais à frente, Bruno Bauer, contemporâneo de Karl, também realizará, em um movimento de cada vez mais proximidade com o ateísmo, críticas importantes a Evangelhos, compreendendo-os como produto da autoconsciência de evangelistas ao invés de ensinamentos de Jesus. A rejeição a Deus torna-se presente em poemas de Karl entre os anos 1836 e 1837, o que, ao que indicam cartas, não aparentou ser difícil visto a forma pela qual ele e sua família relacionavam-se com a religião, sem fanatismos ou proximidades. Neste momento, a amizade entre Bauer e Marx é relatada principalmente por cartas, onde, inclusive, havia a perspectiva de publicação conjunta. Para Heinrich (2018) é provável até mesmo que Karl tenha influenciado o amigo para o ateísmo.

O primeiro volume desta biografia termina com a tese de doutorado de Marx (2018a). O primeiro título - que depois fora modificado para o já apresentado anteriormente - Cadernos sobre a filosofia de Epicuro, revelam um interesse de Karl em discutir o filósofo grego. Provavelmente, esta vontade surge da identificação com as críticas de Epicuro a religião, fazendo com que este fosse renegado por conservadores e religiosos. Grosso modo, a diferença constatada por Marx está no fato de que apesar de ambos partirem do pressuposto da existência do átomo, Epicuro aponta para a importância do acaso no mundo, enquanto Demócrito aproxima-se de uma perspectiva determinista, prendendo o movimento e a presença dos átomos a uma suposta 
necessidade. Segundo Marx, a filosofia de Epicuro estaria baseada, ainda, na divisão entre essência e existência. O debate desenvolve-se até o campo da consciência, onde discute-se a possibilidade da ataraxia (ou tranquilidade) da autoconsciência individual, ou seja, permitindo a consciência individual sem ser interpelada por inquietações, representadas, por exemplo, pela religião. Esta estaria, portanto, em oposição a uma autoconsciência universal-abstrata, existente como parte de um universal divino. A existência de uma autoconsciência não mecanicista, como em Demócrito, permitiria pensar a humanidade nos escritos de Epicuro de forma próxima a como os Iluministas fizeram.

Relacionar Marx com o nascimento da sociedade moderna é, de fato, um dos grandes méritos da biografia realizada por Heinrich (2018). Afinal, assim como é apontado no Manifesto Comunista (MARX; ENGELS, 2015, p.43) que a modernidade é onde "tudo que era sólido e estável se desmancha no ar", também Charles Baudelaire (1996), em Sobre a Modernidade, demonstra, pelas pinturas do fictício G., onde estavam representadas as pompas e solenidades próximas uma da outra, o caráter evanescente da modernidade. As relações sociais, políticas e econômicas antes cristalizadas tornam-se, portanto, dissolvidas. É cada vez mais comum o movimento de Marx como crítica ao capitalismo, possivelmente devido as crises econômicas, financeiras e políticas. Em seu primeiro volume, a biografia já revela como é importante contextualizar a vida do autor, junto de sua produção teórica, para auxiliar na compreensão da construção do seu pensamento e afastar, na medida do possível, mitos e paixões dogmáticas que envolvem sua imagem e memória. Assim, encontra-se uma possibilidade de superação das formas pela qual aproximam-se de Marx hoje apontadas por Netto (2006), ou seja, sem prender-se a dogmatismos, ao uso descontextualizado de seus escritos ou dos que imaginam que Karl Marx já está morto. 


\section{REFERÊNCIAS}

ALTHUSSER, Louis. Por Marx. Campinas, São Paulo: Editora UNICAMP, 2015 .

BAUDELAIRE, Charles. Sobre a Modernidade. Rio de Janeiro: Paz e Terra, 1996.

HEINRICH, Michael. Karl Marx e o Nascimento Da Sociedade Moderna, vol 1. São Paulo: Boitempo, 2018.

MARX, Karl. Diferença Entre a Filosofia da Natureza de Demócrito e Epicuro. São Paulo: Boitempo, 2018a.

. Manuscritos econômico-filosóficos. São Paulo: Boitempo; 2008.

Crítica da filosofia do direito de Hegel. São Paulo: Boitempo, 2010.

O Capital: crítica da economia política: livro I. Rio de Janeiro: Civilização Brasileira, 2004.

. Considerações de um rapaz acerca da escolha de uma profissão. In: HEINRICH, Michael. Karl Marx e o Nascimento Da Sociedade Moderna, vol 1. São Paulo: Boitempo, 2018, pp. 421-424.

; ENGELS, Friedrich. Manifesto do Partido Comunista. São Paulo: Boitempo, 2015.

NETTO, José Paulo. O que é o marxismo. São Paulo: Brasiliense, 2006. 